\title{
ESTONIAN CENSUS 2011
}

\author{
EnE-Margit TiIt
}

\begin{abstract}
In Estonia the census of wave 2010 was organised, as in all states of EU, in 2011. The duration of the census was three months, whereby during the first month the e-census was carried through. $2 / 3$ of the population participated in e-census. Main results of the census were estimated population size that had decreased about $5 \%$ and estimated net external migration that was about 45000 people. About $24 \%$ of Estonia population is foreign-origin, among them $12 \%$ of the first, $8 \%$ of the second and $4 \%$ of the third generation.
\end{abstract}

Keywords: census, migration, foreign-origin population, fertility

\section{ORGANISATION OF CENSUS 2011}

UN organises worldwide a census in each decade. For the members of EU there exists a series of directives that fix the time, methodology and obligatory information to be collected by census.

In Estonia the census of wave 2010 was organised, as in all states of EU, in 2011. The critical moment was 31 December 2011 at 00.00 and the duration of the census was three months - from 31 December 2011 to 31 March 2012. The first month from the critical moment up to beginning of February the e-census was carried through, then all people had the possibility to enumerate themselves by internet. Then followed a short data-processing period, when the list of people to be interviewed was updated. From 20 February the field-work started, when enumerators visited the homes where not all people were e-enumerated and interviewed them, using laptops and also fixed the space coordinates of all livingplaces using GPS-devices. The census finished, as planned, on 31 March 2012.

For identifying the people during e-numeration and also protecting the data several methods were used: Id-card, bank accounts of several banks, mobile- 
phone. The most popular way for entering to enumeration environment was using the bank codes, as e-banking (including filling in the tax declarations) has been very common in Estonia already during last ten years.

As a result, it turned out that about $66 \%$ of all population enumerated was enumerated via internet - the result that no other country had reached. Here media helped very much - the image of census was, in general, positive; the results of enumeration were published on web-site of Statistics Estonia and during e-enumeration the data on absolute number of people enumerated and their percentage (by counties) were updated hourly and these data awoke in Estonian population exaltation as in sporty competition - can we reach the World Record? The idea of record was spoken out by publicists.

\section{MAIN RESULTS OF CENSUS}

The first traditional question is the population size - has the population since the last census increased or decreased and how much? What are the reasons of the change?

Estonian population size by the census 2011 was 1294455 persons and so it followed that it had from the last census, when the size was 1370050 , decreased for about 5\% during 11.7 years. The result was not surprising, as both the natural increase (that was almost all time negative) and net migration (that was negative, too) had been monitored during the period by Statistics Estonia. The only number that was not known beforehand was not-registered emigration.

Although there were made big efforts to reach during the census the whole population, by several reasons about $2 \%$ of the population were not enumerated. Using different registers it was estimated that about 25 000-28 000 people, living permanently in Estonia, were not enumerated and the real population size of Estonia at the census moment was about 1320000 .

At the same time - the population decrease (about 30000 negative natural increase, 20000 registered net migration and 25000 nonregistered net migration) was estimated more or less correctly, but the basic population size for all calculations included also undercoverage error from the census 2000.

\section{ESTIMATION OF EXTERNAL MIGRATION}

Traditionally, census gives good information for analysing immigration, but in general - no information for emigration, assuring the census only permanent 
residents of the country are interviewed and it is not possible to ask questions from the people who have travelled away from the country. Still, in this census several questions about the people emigrated during the last 11 years were put to their relatives or previous household members. Using the information get from the answers to these questions about 30000 emigrants were identified. For checking if they were registered or not registered, their ID-codes ${ }^{1}$ (more exactly: encrypted ID-codes) were compared with Population Register (PR) and it turned out that more than half of them were still in PR as the residents of Estonia, that means, if they had left Estonia, then without registering. Almost half of legally emigrated people were also indicated on census questionnaires. The last fact was not surprising, as among emigrants there were several households that did not have remaining close people in Estonia.

\section{Foreign-origin population}

More detailed information was collected about immigration. It was evident that among Estonian residents there was 170000 persons who had immigrated from other countries, see Figure 1.

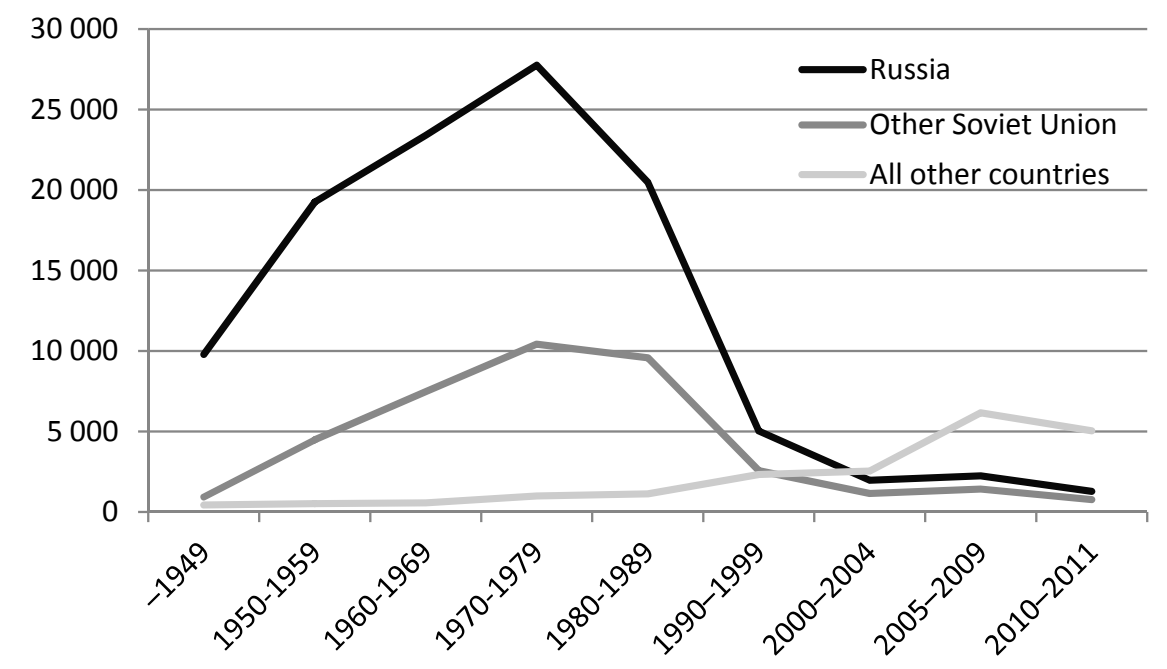

Figure 1. Immigration from other countries (absolute number of immigrants)

1 During the data-processing and analysis crypted ID-codes were used that did not allow to identify the persons, and see their data, but only to combine data from different data sources (registers, censuses). 
As during the census 2011 the birth-places of persons' parents and also grandparents were asked, so it was possible to analyse the population by their origin much more in-depth than it was done earlier.

The population of Estonia has been divided into native and foreign-origin population as follows:

- Native population - persons permanently living in Estonia, at least one of the parents and at least one of the grandparents of whose were born in Estonia.

- Foreign-origin population - persons permanently living in Estonia who do not belong to the native population. Foreign-origin population has been divided into the first, second and third generation as follows:

- the first generation of foreign-origin population - persons permanently living in Estonia who and whose parents were born abroad;

- the second generation of foreign-origin population - persons permanently living in Estonia who were born in Estonia but whose parents were born abroad;

- the third generation of foreign-origin population - persons permanently living in Estonia of whose parents at least one was born in Estonia but whose all grandparents were born abroad.

From the total population of Estonia the native population forms $75 \%$, the first generation of foreign-origin population - 13\%, the second generation - $8 \%$ and the third population - 4\%. Due to immigration policy in Soviet Union, the different generations of immigrants have different age structure: the mean age of the first, the second and the third generation is 61, 42 and 25 years. Also the ethnic structure differs slightly by generations, see Figure 2, showing some tendency to converge towards bigger ethnic groups, especially towards Russians. Concerning the citizenship, similar tendency occurs, but with the concentration towards Estonian citizenship, see Figure 3.

Similar tendency can be observed also in the case of command of Estonian language (see Figure 4): the second generation who has completed schools in Estonia, knows Estonian somewhat better than the first generation, but the command of Estonian language has not improved in the case of the third generation of foreign-origin population, who has got the education in Estonian Republic. Hence, there are problems in integration and education policy, about half of young and middle-aged non-Estonians born and educated in Estonia so not know Estonian language, although their education level is, in general, quite high. 


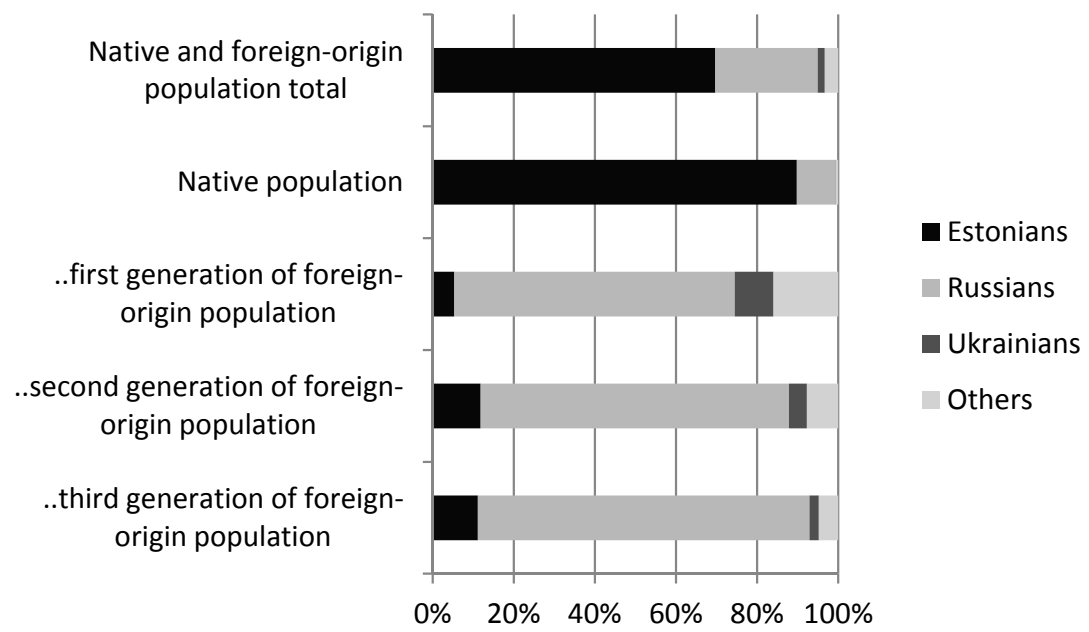

Figure 2. Ethnic structure of native and foreign-origin population

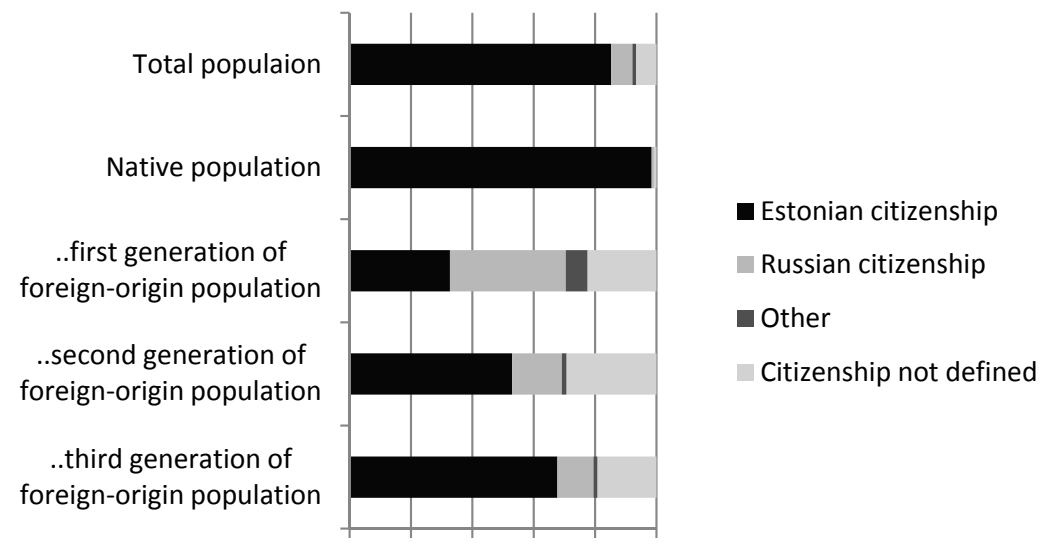

0\% 20\% 40\% 60\% 80\%100\%

Figure 3. Citizenship of native and foreign-origin population

Similar tendency can be observed also in the case of command of Estonian language (see Figure 4): the second generation who has completed schools in Estonia, knows Estonian somewhat better than the first generation, but the command of Estonian language has not improved in the case of the third generation of foreign-origin population, who has got the education in Estonian Republic. Hence, there are problems in integration and education policy, about half of young and middle-aged non-Estonians born and educated in Estonia so not know Estonian language, although their education level is, in general, quite high. 

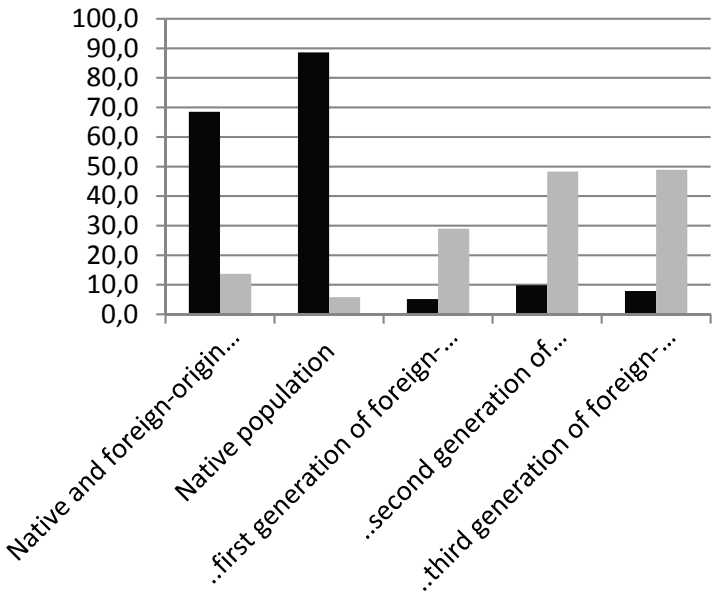

Figure 4. Command of Estonian language -..the Estonian language is the mother tongue

\section{-..command of the Estonian} language as a foreign language

\section{INTERNAL MIGRATION}

When following the internal migration, the counties differ from each other quite a lot, see the Figures 5 and 6.

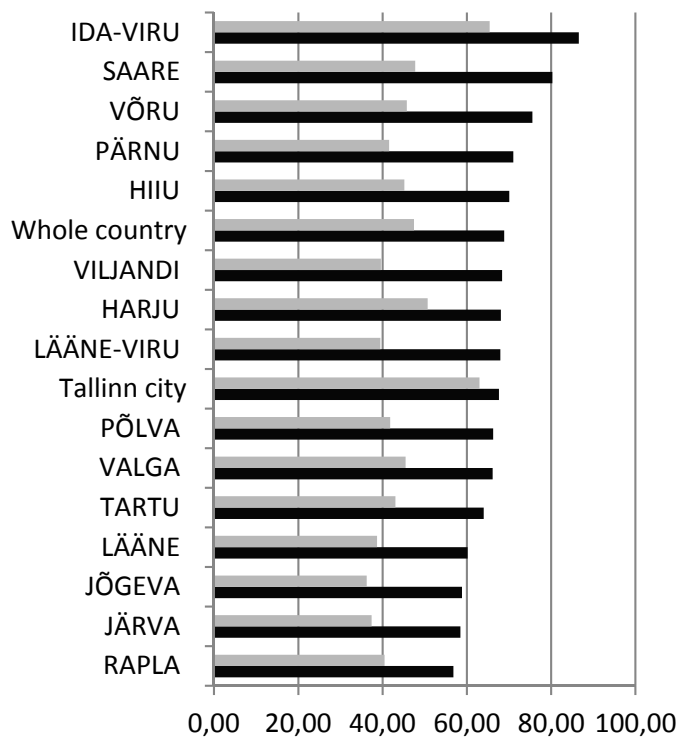

-..place of birth in city / rural municipality of residence

Place of birth in county of residence

Figure 5. Share of people, living in the county and in the city or rural municipality were they were born 
From the Figure 5 it follows that the interior migration in Estonia has been rather active: about one third of residents (of all ages) who have born in Estonia, do not live in the county where they have born and less than half live in the city or rural municipality where they were born. It is important to mention that the place of birth considered in census is a place (country, administrative unit) where the person's mother was a (permanent) resident at the time of the person's birth.

Comparing the counties it follows that Ida-Virumaa's population is the most conservative about their living-places: from all persons born in Ida-Virumaa and still living in Estonia, 87\% live in Ida-Virumaa and 65\% live in the same city or rural municipality. The Capital city is the place where people like to live - from all people born in Tallinn, 63\% live still in it.

Population of such counties as Jõgeva, Järva, Lääne and Rapla is the most mobile - in average, less than $60 \%$ of people born in these counties live there nowadays and less than $40 \%$ live in the city/rural municipality where they are born.

Recent tendencies of interior migration are illustrated by the Figure 6.

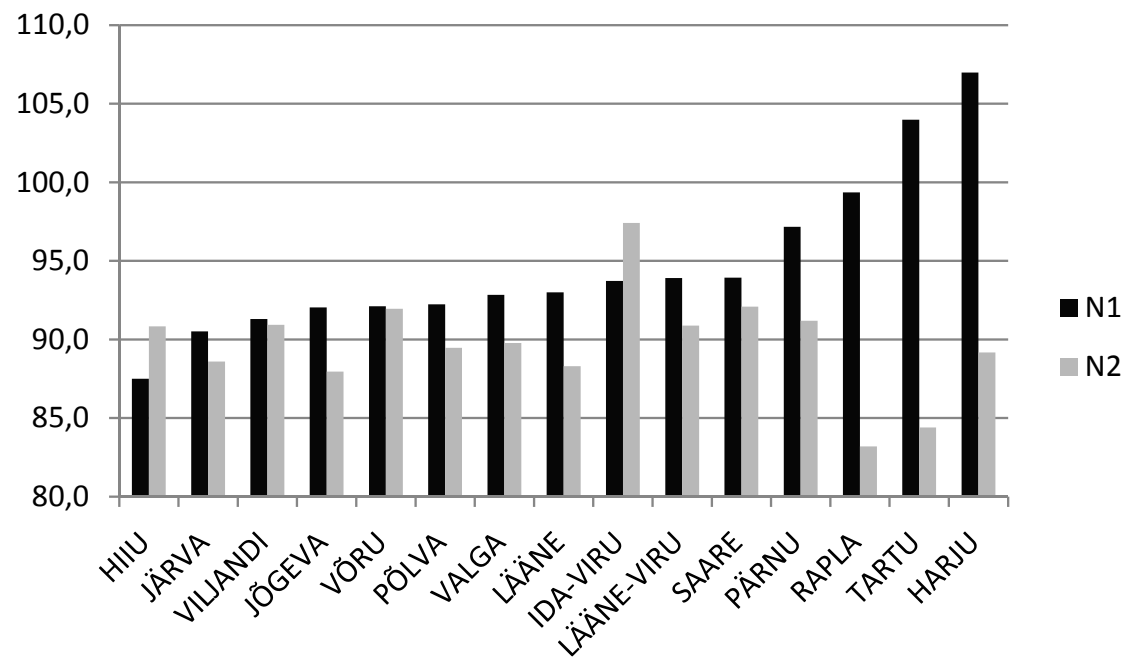

Figure 6. Internal migration between censuses 2000 and 2011. N1 is the number of residents living in county in 2011 compared with the number on residents lived in the county in 2000; N2 is the \% of people who have been living in the same county on both censuses compared with the number of population in 2011. In both indicators only the people living in Estonia 2000 and 2011 are considered. 
Two counties - Harju and Tartu - have gained a big amount of population from other counties and their population has been increased markedly. Similar tendency is also in Rapla county, it has lost a few of its population, but this loss is not as big as in other counties. Again, Ida-Viru demonstrates the stability (or closeness) of its population: only 5\% of population born in Ida-Virumaa and still living in Estonia have left from Ida-Viru to other counties since 2000. Hiiu, Järva, Viljandi and Jõgeva have lost the biggest amount of population. Jõgeva and Lääne county's population has been quite mobile, but as a result they have lost big part of it. In general, two tendencies occurred in interior migration:

1. The people left peripherial areas and moved towards centrums;

2. The people left the cities and moved to the areas nearby cities.

As the result, the villages far from centres emptied and the population's age structure changes: in villages and cities that have lost part of population, mainly elderly population has remained. On the opposite, the villages near big cities have quite young population. Also the distribution of population by sex has changed - in many villages there live more men in young working age (20-35) than women, in big cities in this age the women are over-represented.

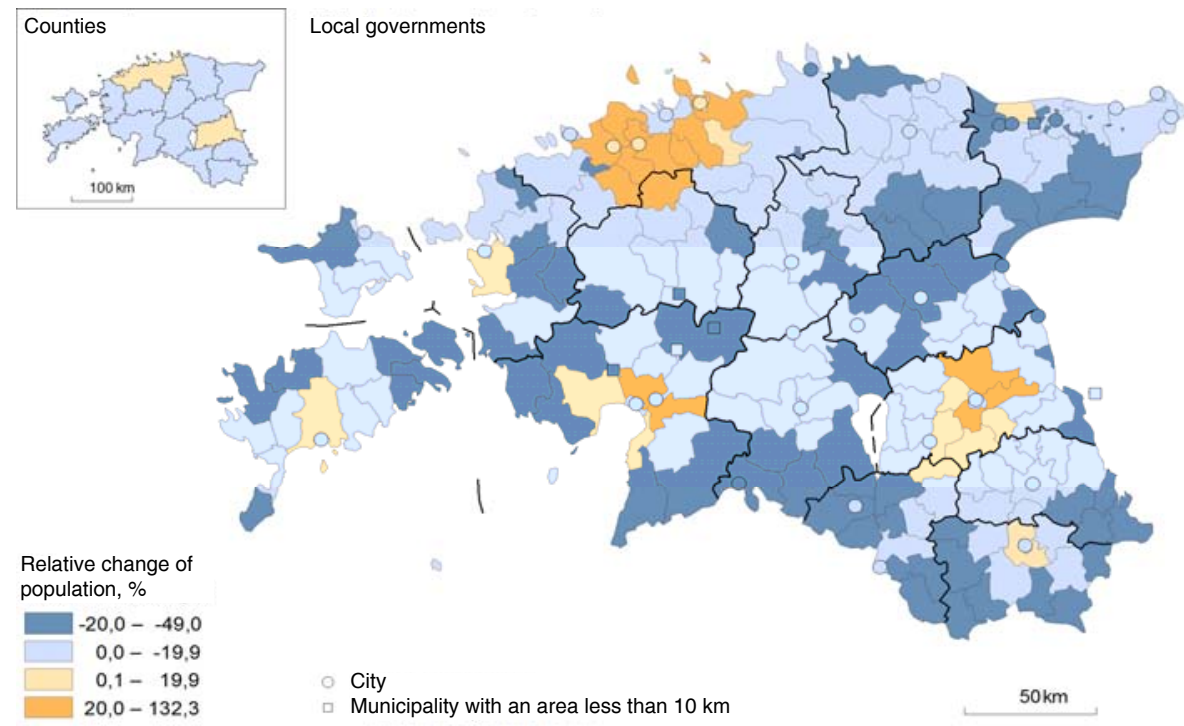

Figure 7. Relative change of population in period $2000-2011$ by municipalities 


\section{FERTILITY TRENDS}

Using the census data it was possible to estimate the finished number of children for the women's cohorts born in 1940-1970. The result was surprisingly positive: Estonian women of these cohorts had the number of children that reached the critical number 2 (after very many generations).

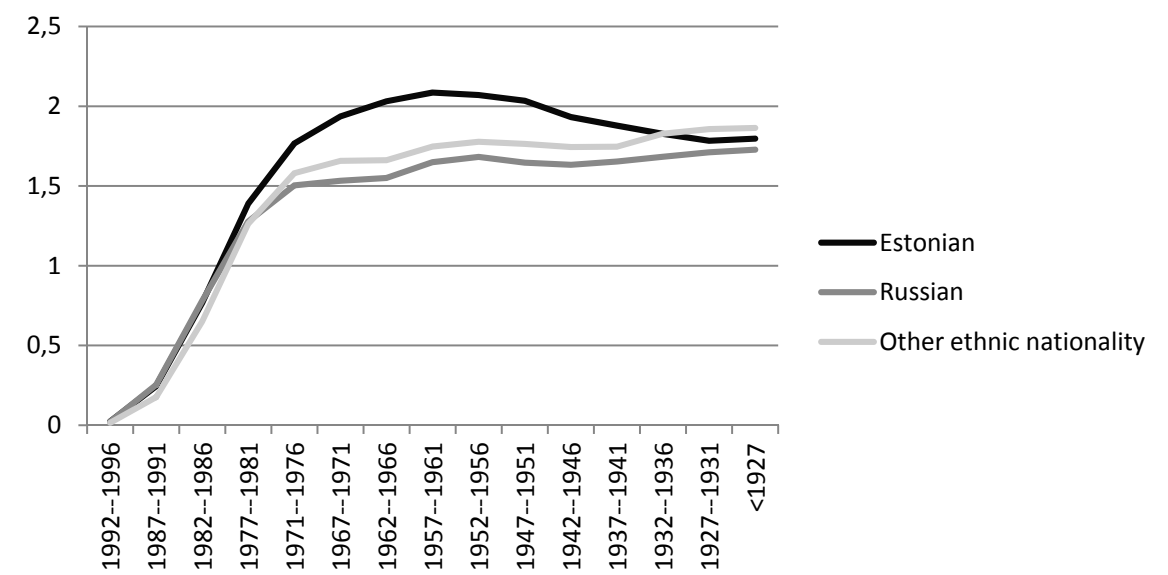

Figure 8. Number of children born depending on the birth cohort and ethnic nationality of mother

Table 1. Average number of children depending on marital status, educational attainment and living space of a woman aged 15-49

\begin{tabular}{lcccccc}
\hline & \multicolumn{2}{c}{$\begin{array}{c}\text { Lower secondary or } \\
\text { less }\end{array}$} & \multicolumn{2}{c}{ Upper secondary } & \multicolumn{2}{c}{ Higher education } \\
\cline { 2 - 7 } & $\begin{array}{l}\text { Urban } \\
\text { settle- } \\
\text { ments }\end{array}$ & $\begin{array}{c}\text { Rural } \\
\text { settle- } \\
\text { ments }\end{array}$ & $\begin{array}{l}\text { Urban } \\
\text { settle- } \\
\text { ments }\end{array}$ & $\begin{array}{c}\text { Rural } \\
\text { settle- } \\
\text { ments }\end{array}$ & $\begin{array}{l}\text { Urban } \\
\text { settle- } \\
\text { ments }\end{array}$ & $\begin{array}{c}\text { Rural } \\
\text { settle- } \\
\text { ments }\end{array}$ \\
\hline $\begin{array}{l}\text { Living with } \\
\text { legal spouse }\end{array}$ & 1.92 & 2.61 & 1.75 & 2.28 & 1.7 & 2.07 \\
\hline Cohabiting & 1.38 & 1.93 & 1.10 & 1.61 & 1.08 & 1.48 \\
\hline $\begin{array}{l}\text { Living without } \\
\text { a partner }\end{array}$ & 0.31 & 0.39 & 0.67 & 0.91 & 0.76 & 1.04 \\
\hline
\end{tabular}

From the Table 1 it becomes evident that both marital status and living place have quite strong influence on the fertility of women. But the comparison of cohabiting and married women gives skewed result as in average, cohabiting women are younger than married ones. When we compare the women of the same age, the difference in the average number of children is much less. Difference between urban and rural women is partly connected with their ethnic 
nationality: in rural areas live mainly Estonians, the Russians and represenatatives of other nationalities live, in general, on cities. The influence of educational level exists, too, but is not very strong. In the case of women living with partner, the higher education means in average less children. For the women living without a partner, the tendency is opposite - the people with higher education have in average more children.

\section{EDUCATION}

The education level in Estonia was quite high: about 30\% of residents (age $\geq 10$ years)had higher education, about $40 \%$ - upper secondary and $30 \%$ lower secondary or less. Most of people having low education are either young (age $\leq 20$, who have not completed their education yet) or elderly (age $\geq 65$, who completed their education long ago and do not have motivation to update it). That means, in $201170 \%$ of the whole population (age $\geq 10$ years) had no less than higher secondary education. Twelve years ago this share was less than $50 \%$.

In Estonia the difference of men and women in education is quite large, especially in the highest level: $35 \%$ of women and $24 \%$ of men have the higher education. Men have been somewhat more active in getting professional education (after upper secondary) - there are $20 \%$ of women and $26 \%$ of men who have such education. Among the people having lower secondary education the men are dominating (32\% against women's $26 \%$ ) in spite of the fact that the number of elderly (age $\geq 65$ ) women is more than twice larger than the number of men of this age.

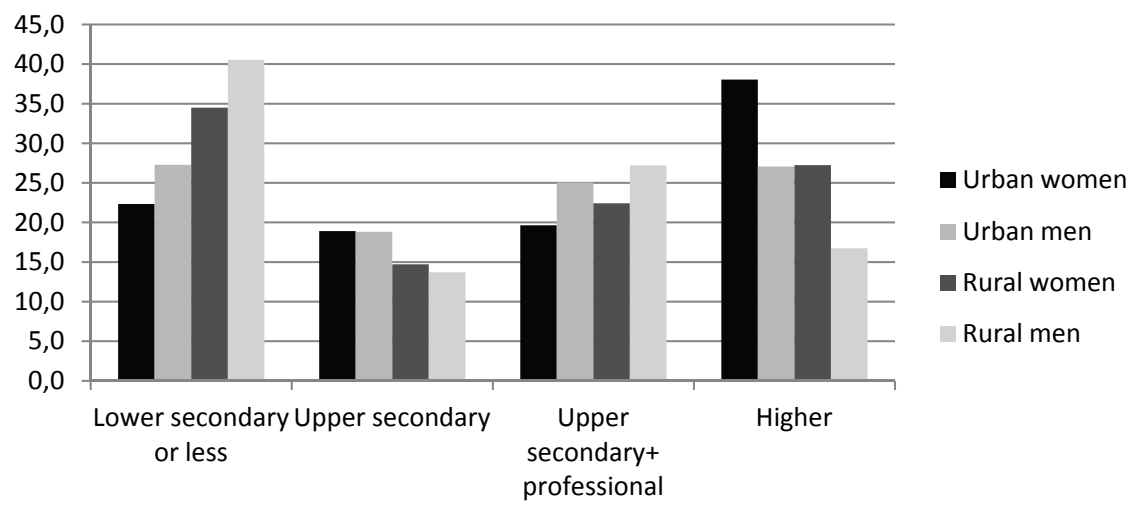

Figure 9. The education level of men and women depending on their living place 
The difference between education levels in urban and rural regions is quite large. In urban region the share of men and women having higher education is about $10 \%$ higher than in rural areas, and the difference in upper secondary education is about $5 \%$.Only the professional education is in rural areas somewhat more popular (for 2-3\%) than in urban region.

\section{HEALTH}

The first time in Estonia the census data were used to estimate the DFLE (disability free life expectancy). For this aim the following two census questions were used "Do you have any long-term illness or health problem?" and "Do you have limitations on every-day activities due to health problems?” For estimating the number of people having disabilities, the people who had answered that their activities are very much restricted were used.

As a result the following results for men and women were received, see Figure 10.

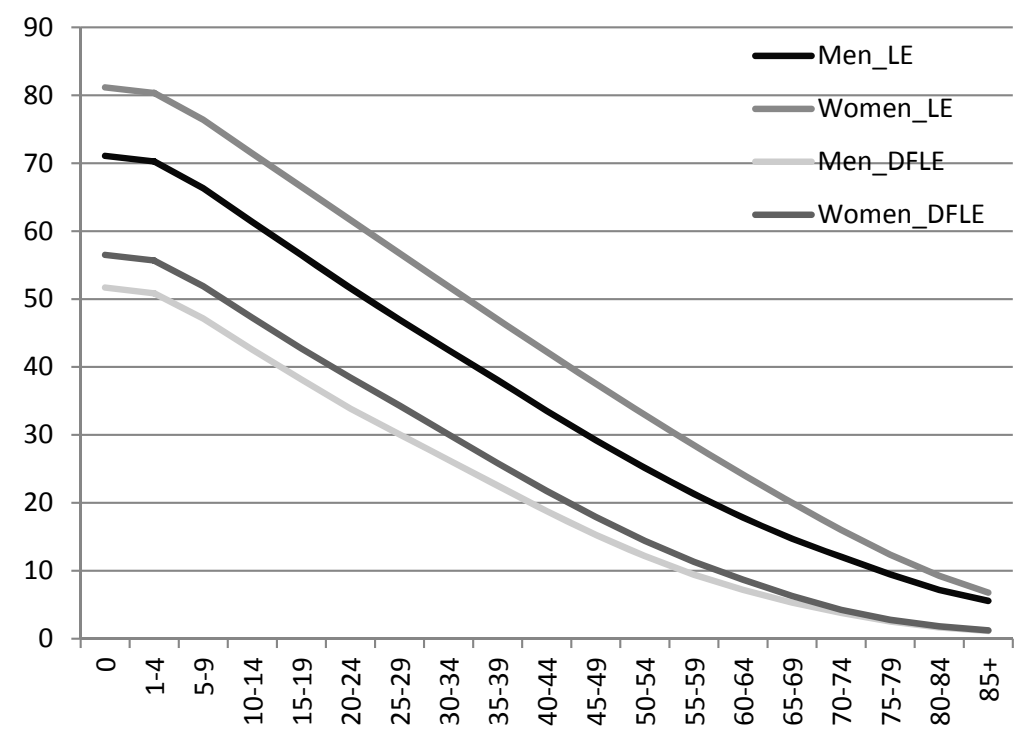

Figure 10. Life expectancy (_LE) and disability - free life expectancy of men and women depending on their age 
It was evident that the life expectancy (LE) had during the last 11 years increased for more than 5 years that is in fact a very good result, but still the life expectancy in born - 71 years for men and 81 years for women is rather modest for EU countries. Especially problematic is the big difference -10 years - between the women's and men's LE. The comparison of life expectancy and DFLE shoes that, in general, women's life with health problems is longer than men's such life. Women live without problems $70 \%$ of their life, that is 57 years, men $-73 \%$ or 51 years. Of course, these number are abstract, as they respond to the situation when the mortality and morbidity trends do not change and the situation of today will remain for the whole lifetime of a people. As this assumption is unrealistic, hence probably the children who have born this year, will live much longer, also will have, in average, much longer disability-free life.

\section{CONNECTION BETWEEN EDUCATION AND HEALTH}

The fact that people having higher education have also longer life expectancy has been established already many years ago, since these indicators both were measured and analysed. As a result of the last census also connection between health and education was analysed and quite strong influence of education on the DFLE was established.

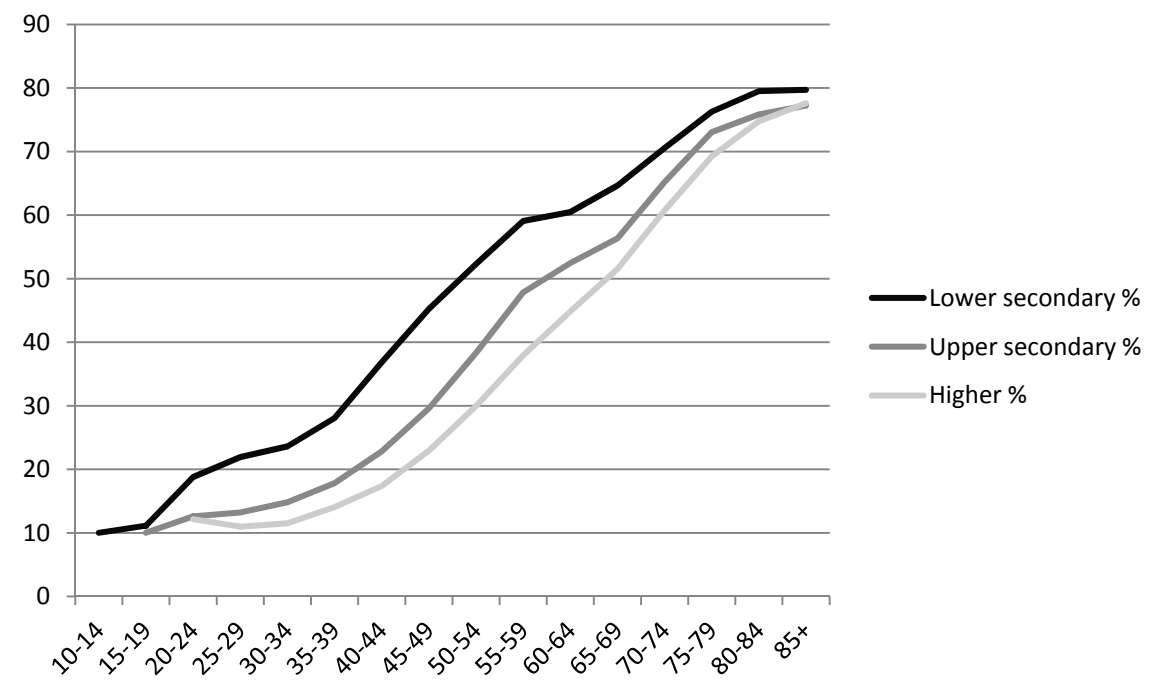

Figure 11. Probability of having health problems restricting the usual activities significantly 
The Figure 11 shows that the people having higher education have in age 20-39 years health problems restricting their activities with probability 0,12 , the people with lower secondary education or less - with probability 0,23 , that means, the probability is almost twice higher. From here it turns out that learning a year more gives to a person additionally more than a year disability-free life, and the difference is the biggest in younger working age. More is detail - the influence of education is stronger for men compared with women and stringer in countryside than in cities. Probably, the reason of these differences is connected with the occupation or position of a person, that might be more dangerous for the people having lower education. Also it might be connected with preconditions - the people having worse health do not reach so high educational level. Still the main reason is probably the difference in living styles that are different for the people having different education level and belonging to different social groups. Also the people having lower education, in general, have smaller income and since have less possibilities to take care on their health. Also, it might be connected with the information.

Source of information: Statistical Database of Statistics Estonia, http://www.stat.ee/en

\section{Address for correspondence:}

Ene-Margit Tiit

Institute of Mathematical Statistics

University of Tartu

J. Liivi 2-509, Tartu

E-mail: ene.tiit@ut.ee 